Article title: Reflections on Post-Conference Feedback as a Developmental Teacher Training Strategy: Teaching Practice Supervisors' Experiences in an ODL Institution

Authors: Tshegofatso Makgakga[1], Sindile Ngubane-Mokiwa[2]

Affiliations: Department of Mathematics Education, CEDU, University of South Africa[1], Institute for Open Distance Learning, University of South Africa[2]

Orcid ids: 0000-0003-0998-7828[2]

Contact e-mail: ngubasa@unisa.ac.za

License information: This work has been published open access under Creative Commons Attribution License http://creativecommons.org/licenses/by/4.0/, which permits unrestricted use, distribution, and reproduction in any medium, provided the original work is properly cited. Conditions, terms of use and publishing policy can be found at https://www.scienceopen.com/.

Preprint statement: This article is a preprint and has not been peer-reviewed, under consideration and submitted to UnisaRxiv for open peer review.

DOI: 10.25159/UnisaRxiv/000021.v1

Preprint first posted online: 26 May 2021

Keywords: teaching practice, post-conference feedback, student support, practicum, pre-service teachers 


\title{
Reflections on Post-Conference Feedback as a Developmental Teacher Training Strategy: Teaching Practice Supervisors' Experiences in an ODL Institution
}

\author{
T. P. Makgakga \\ https://orcid.org/0000-0002-6602-4924 \\ College of Education, University of \\ South Africa
}

\author{
S. A. Ngubane \\ https://orcid.org/0000-0003-0998-7828 \\ Open and Distance Learning Research \\ Unit, University of South Africa \\ ngubasa@unisa.ac.za
}

\begin{abstract}
Nationally and internationally, higher education institutions offer teaching practice as one of the teacher training support strategies to develop pre-service teachers' pedagogical knowledge and skills. The University of South Africa is one of the higher education institutions that offer open and distance learning and has a high number of pre-service teachers. The University's teaching practice is supervised by experts and culminates in a conferencing session in which the supervisor provides feedback on various aspects of the teaching practice. This study explored the teaching practice supervisors' reflections on post-conference feedback as a developmental approach towards reinforcing assessment for learning. The qualitative approach was used as the researchers interpreted these supervisors' reflections on post-conference feedback as a developmental approach. Through purposive sampling, supervisors who had supervised preservice teachers for three or more years were selected. The findings of this study showed that post-conference feedback was developmental to pre-service teachers and supervisors. The findings further illuminated the way in which supervisors had assessed pre-service teachers' teaching skills to understand their strengths and weaknesses. In addition, the study identified pitfalls such as time and the supervisor-to-pre-service-teacher ratio as 1:10 per week, which was unsustainable. The study suggests that there is a need to set clear and specific outcomes for assessment, to provide a self-assessment rubric for pre-service teachers to avoid conflicts during the post-conference feedback, and to arrange professional development workshops to be conducted with the supervisors.
\end{abstract}

Keywords: teaching practice, post-conference feedback, student support, pre-service teachers, practicum 


\section{Introduction}

Higher education institutions (HEIs), nationally and internationally, offer teaching practice as one of the teacher training support strategies to develop pre-service teachers' pedagogical knowledge and skills they require to teach. Teaching practice (TP) is of great importance for teacher training institutions to develop in-service teachers' pedagogical skills. Abdulla and Mirza (2020) argue that TP provides pre-service teachers with a set of opportunities designed to help them to become good teachers. Gürsoy (2013) concurs that TP is vital for both the teacher trainer and pre-service teacher. Moreover, TP provides pre-service teachers with an opportunity to perceive their level of skills, to correct specific mistakes and to improve their weaknesses (Kale 2011). Copland (2010) stresses that TP provides support to pre-service students through the experienced teachers who teach in the schools where those students are placed and supervisors from institutions that award qualification programmes.

Pre-service teachers are able to apply theoretical knowledge learned during TP. In this regard, Surucu0, Unal and Yildirim (2017) argue that the theoretical knowledge of preservice teachers can only make sense when they possess the knowledge, skills, attitudes and behaviours they need in classroom practice. The experienced teachers and TP supervisors provide pre-service students with skills and knowledge on how to teach and how to improve those skills during TP sessions. Copland (2010) argue that the experienced teacher and the supervisor offer pre-service teachers support as they learn how to teach, provide suggestions and advice during TP to improve practice, and assess students through a set of criteria. However, the reflection on post-conference feedback by the supervisors and pre-service teachers appears to have been given little attention.

The University of South Africa (Unisa) is an open distance learning (ODL) institution which offers teacher training programmes such as the Postgraduate Certificate in Education (PGCE) and Bachelor of Education (BEd) for the foundation, intermediate, senior and further education and training (FET) phases in the College of Education (CEDU). TP is a compulsory component for all pre-service teachers enrolled for the two programmes in the CEDU (Unisa 2012). All pre-service teachers are expected to spend 10 weeks in schools, the first five consecutive weeks and the last five consecutive weeks in different schools. The first two weeks in schools are allocated to classroom observations and the other remaining weeks are for teaching in the classroom. The placement of pre-service students is diverse in schools in terms of learners, teachers and how resourceful the school is. The students are expected to commit themselves in all the activities that need their attention during TP sessions.

Unisa (2012) postulates that TP plays a central role in the initial professional education and training (IPET) curriculum for teachers. The IPET is divided into four interrelated competences for pre-service teachers, including becoming a teacher, a subject or learning specialist, a teaching and learning specialist, and school and profession. It is also argued that TP is the core of the IPET curriculum, progressing from observation to assisting, from team teaching to independent teaching, and cutting across all four 
competences (Unisa 2012,20). For the pre-service teachers to master the four interrelated competences in schools, the supervisor and the experienced teachers should be present to observe teaching and to provide feedback after the lessons.

In Unisa's (2012) manual, the pre-service teachers are allocated a mentor teacher at school level and a supervisor to assess them during TP. The mentor teacher is assigned to assist pre-service teachers with activities, practices, feedback and advice on a regular basis. The supervisor is assigned to work jointly with the mentor teacher to observe and assess one lesson presented by the pre-service teacher. Both the supervisor and the mentor teacher should conduct both pre-conference and post-conference meetings to provide feedback to the student after the lesson presentation. Unisa conducts seminars with the mentor teachers to train and empower them to mentor student teachers during TP sessions. However, TP supervisors' reflection on post-conference feedback can be essential for the TP supervisors, mentor teachers and pre-service teachers to understand their experiences during the TP sessions. This can provide guidance on the implementation of TP policies and their practices in schools.

Unlike pre-service teachers in conventional universities, Unisa students do not have an opportunity to come face-to-face with their lecturers. This study shares ODL supervisors' reflections on post-conference feedback as pre-service teachers' support strategy during TP supervision, to understand if assessment for learning (AfL) with the pre-service teachers is reinforced. As post-conference feedback is conducted after classroom observations, our research elucidates a gap between summative assessment that occurs during classroom observations and formative assessment that occurs during post-conference feedback. This study was guided by the following research questions: (1) What are ODL supervisors' reflections on post-conference feedback during TP supervision? (2) How do their reflections inform best practices in teacher training through ODL?

\section{Post-Conference Feedback Sessions}

Copland (2011) argues that post-observation feedback conferences are common in the teacher education programmes during TP sessions. Copland (2008) maintains that for the experienced teachers and supervisors to perform their duties during TP, they should hold feedback sessions after lesson presentations by pre-service teachers. Tang and Chow (2007) affirm that communicating feedback is vital to professional learning in many professions, including teacher education. The scholars indicate that supervision in the form of lesson observation and post-observation conferences and the communication of constructive feedback in the supervisory conferences are all essential to teachers' professional development (Tang and Chow 2007, 1066). Ali and Al-Adawi (2013) argue that feedback on TP can develop student teachers' pedagogical and teaching skills through oral and written interaction. Calleja et al. (2016) add that feedback sessions promote students' thinking and reflection on their skills while consolidating their pedagogical skills. This happens because in feedback sessions, 
students are provided with positive and negative evaluations of their teaching and the suggestions for improvement (Copland, Ma, and Mann 2009).

In the same vein, Wells and McLoughlin (2014) point out that feedback on performance helps students to learn and meet professional standards during work-integrated learning placements. Furthermore, feedback helps students to make goals and to set clear objectives for future learning and improvement in their performance (Calleja et al. 2016). In addition, Gürsoy (2013) asserts that experienced teachers and supervisors' feedback depends on their knowledge and skills, and that the quality and quantity of the feedback may differ for each pre-service teacher.

Studies have been conducted on feedback during TP and include studies such as the negotiation of face in post-observation feedback conference (Copland 2011), causes of tension in post-observation feedback (Copland 2010), communicating feedback in TP supervision (Tang and Chow 2007), providing effective feedback (Ali and Al-Adawi 2013; Martinez Agudo 2016), the nature of feedback (Akcan and Tatar 2010; Copland, Ma, and Mann 2009), the effect of a more intense practicum with an increased number of observations and feedback hours (Gürsoy 2013), feedback on performance (Wells and McLoughlin 2014), and feedback and clinical improvement (Calleja et al. 2016).

In a study conducted by Martinez Agudo (2016), qualitative and quantitative research methodologies were used to investigate the Spanish EFL student teachers' needs and expectations from their school mentors during TP. The results of the study revealed a high degree of satisfaction among student teachers regarding effective feedback provided by the mentor teachers. Ali and Al-Adawi's (2013) study, conducted in the United Kingdom (UK), supports the notion that TP feedback has positive results; however, the students revealed that although both oral feedback and written feedback were important to them, they all preferred written feedback. However, the study of Martinez Agudo highlighted a gap between the quality feedback provided by mentor teachers and student teachers' expectations and satisfactions during their professional learning. For example, the study revealed a lack of detailed feedback and confidence towards student teachers by mentor teachers during lesson presentations. Kemmis et al (2014) suggested that TP could be an ongoing process of reflection and cooperation between student teachers, mentor teachers and university supervisors.

Akcan and Tatar (2010) investigated the nature of feedback to the English pre-service teachers during TP in Turkey. The study sought to understand the way in which university supervisors and cooperating teachers provided feedback to students during TP and the nature of the feedback given through post-observation conferences and written evaluations. Classroom observations, post-observation conferences between supervisors, incorporating teachers and students, written evaluation sheets and documents were used to collect data. The findings of the study show that the supervisors' feedback had mostly encouraged reflections and helped students to critically evaluate their lessons during post-observation conferences. The feedback 
provided by the teachers to students also had only focused on certain instances of classroom practice.

Feedback is vital in TP, but it can cause tension in the process (Brandt 2008). Brandt $(2008,361)$ suggested that supervisors and students have conflicting expectations regarding the purpose of the TP element:

from the tutor's perspective, it is there (in significant) to facilitate assessment; while from the trainee's perspective, it exists to allow them to develop skill and proficiency in the work of teaching.

Brandt further suggested that assessment and development do not work hand in hand during feedback sessions. This opinion is supported by Holland (2005) who opines that assessment and supervision can cause tension during feedback sessions either between supervisor and student or between mentor teacher and student.

Copland (2010) investigated the causes of such tension in post-observation feedback with pre-service teachers who registered for two courses in the UK. The study used interviews with four trainers before and after the course and nine trainees after the course. The findings showed that tension can be caused by the different expectations among trainers and trainees of the purpose and performance of feedback. The findings suggested that tension can cause trainees not to play the game according to the rules, with trainees possibly not understanding the rules or perhaps wishing to challenge those rules.

Gürsoy (2013) postulates that the TP process has to be restructured and standardised to improve teacher training in Turkey. This study used questionnaires, semi-structured interviews and the researcher's field notes to investigate the effects of a more intense TP with an increased the number of observations and feedback hours. Gürsoy argues that the flexibility and limited feedback hours cause inconsistencies in the teacher education which may ultimately limit student teachers from becoming good teachers. Furthermore, the inconsistencies of TP, inflexible implementation, and limited hours for feedback can contribute towards bridging theory and practice.

\section{Conceptual Frameworks}

\section{Relational Practice}

Grossman et al. (2009) proposed a framework called relational practice to guide the implementation of TP for pre-service professionals. This framework is relevant for this paper because it informs the exploration of the way in which practice is imparted in a university-based learning context - teacher training course in this instance. The main elements of relational practice are (i) representations, (ii) decompositions, and (iii) approximations of practice. Representations of practice informs the pre-service teachers of the way in which teaching is represented professionally; the representations 
can vary depending on the environment and perceptions of the novice teachers. Decomposition of practice is about breaking down the components of TP for the preservice teacher to know and learn how to be a good professional teacher. Approximation of practice involves giving the pre-service teacher an opportunity to perform teaching duties in preparation to be a good professional teacher. These elements can inform the post-conference feedback session.

\section{Assessment for Learning}

AfL is defined as "the process of seeking and interpreting evidence for use by learners and their teachers to decide where the learners are in their learning, where they need to go and how best to get there" (Broadfoot et al. 2002, 2-3). Sutton $(1995,264)$ argues that AfL is "part of everyday practice by students, teachers and peers who seek, reflect upon and respond to information from dialogue, demonstration and demonstration in ways that enhance ongoing learning". In principle, AfL is suitable to guide postconference feedback as it promotes student-centred learning and aims to facilitate adaptive learning to ensure student success.

\section{Ten Principles of Assessment for Learning}

\section{Effective planning of teaching and learning}

TP supervisors should provide an environment that enables the pre-service teachers to sharpen their teaching skills. This enabling environment should be flexible in nature, taking diverse ideas and skills into consideration. Pre-service teachers should have a critical understanding of the teaching and learning goals.

\section{Focus on how students learn}

Research has proven that not all students learn the same way. It is therefore imperative that the process of learning takes into consideration the different ways in which students learn.

\section{Recognised as central to classroom practice}

Much of what teachers and learners do in classrooms can be described as assessment, that is, tasks and questions prompt learners to demonstrate their knowledge, understanding and skills. What learners say and do is then observed and interpreted, and judgements are made about the way in which learning can be improved. These assessment processes are an essential part of everyday classroom practice and involve both teachers and learners in reflection, dialogue and decision-making.

\section{Regarded as a key professional skill for teachers}

Teachers require the professional knowledge and skills to plan for assessment, observe learning, analyse and interpret evidence of learning, give feedback to learners, and support learners in self-assessment. Teachers should be supported in developing these skills through initial and continuing professional development. 


\section{Sensitive and constructive}

Teachers should be aware of the impact that comments, marks and grades can have on learners' confidence and enthusiasm and, so they should be as constructive as possible in the feedback that they give. Comments that focus on the work rather than the person are more constructive for both learning and motivation.

\section{Account for the importance of learner motivation}

Assessment that encourages learning fosters motivation by emphasising progress and achievement rather than failure. Comparison with others who have been more successful is thus unlikely to motivate learners, as it can also lead to their withdrawing from the learning process where they have been made to feel they are "no good". Motivation can be preserved and enhanced by assessment methods which protect the learner's autonomy, provide some choice and constructive feedback, and create opportunity for self-direction.

\section{Promote commitment to learning goals and a shared understanding of the assessment criteria}

For effective learning to take place, learners need to understand what it is they are trying to achieve - and want to achieve it. Understanding and commitment follow when learners have some part in deciding goals and identifying criteria for assessing progress. Communicating assessment criteria involves discussing them with learners using terms that they can understand, providing examples of the ways in which the criteria can be met in practice and engaging learners in peer- and self-assessment.

\section{Constructive guidance to improve}

Learners need information and guidance to plan the next steps in their learning. Teachers should pinpoint the learner's strengths and advise how to develop them, be clear and constructive about any weaknesses and the way in which they might be dealt with, and provide opportunities for learners to improve upon their work.

\section{Develop learners' capacity for self-assessment}

Independent learners could seek and gain new skills, new knowledge and new understandings. They can engage in self-reflection and identify the next steps in their learning. Teachers should equip learners with the desire and the capacity to take charge of their learning through developing the skills of self-assessment.

\section{Recognise the full range of achievement of all learners}

AfL should be used to enhance learners' opportunities to learn in all areas of educational activity. In addition, it should enable all learners to achieve their best and to have their efforts recognised. 


\section{Methodology}

The rationale for this study was to understand the TP supervisors' experiences of preservice teachers' TPs during the reflection on post-conference feedback as a developmental approach. The study followed a qualitative approach to interpret and make meaning of the supervisors' experiences of post-conference feedback with preservice teachers during TP sessions. The participants of this study were the TP supervisors who are lecturers in the CEDU at Unisa and have supervised pre-service teachers enrolled for the BEd. The TP supervisors who participated in this study had taught the undergraduate BEd degree for more than five years and they have knowledge of teaching this qualification. Furthermore, the targeted group had participated in the $\mathrm{TP}$ of pre-service teachers for three or more years.

Purposive sampling was used with the supervisors who are lecturers in the CEDU at Unisa. Creswell and Creswell (2018) suggest that for qualitative studies, the researchers can purposefully select participants and sites which can give those researchers an opportunity to understand the research problem and questions. A total of 11 open-ended questions were administered to $22 \mathrm{TP}$ supervisors from various departments in the same college. The questionnaire was designed to be completed in 20 to 25 minutes. The questionnaire had 11 open-ended questions for the participants. The researchers could not use face-to-face interviews owing to the tight schedules of the participants who volunteered to respond to the questionnaire instrument at their own time and place. The rationale for the questionnaire was to obtain data from the TP supervisors' views about supervision of TP, to get their background knowledge about TP before engaging them on their views about post-conference feedback, to determine the purpose of conducting post-conference feedback during TP and the way in which they conducted it, to determine the challenges (if any) faced by both the supervisors and pre-service teachers, to determine pre-service teachers' opportunities to reflect on lessons, to determine the development of pre-service teachers' professional learning and improvement on teachers' TP skills, to obtain general comments and reflection on post-conference feedback, and to determine in which way the ODL TP framework can be improved.

The study obtained a blanket ethical clearance from the CEDU at Unisa, which focused on undergraduate student support. The study followed Israel and Hay's (as cited in Creswell and Creswell 2018,88) ideas on ethical considerations where researchers should "protect their research participants, develop a trust with them, promote the integrity of research, guard against misconduct and impropriety that might reflect on their organisations or institutions, and cope with new, challenging problems". The researchers explained to the supervisors that participation was voluntary and that there was guarantee of anonymity by using pseudonyms. The supervisors were also assured that all information would be used only for the purpose of this study. Furthermore, the supervisors were promised they could withdraw at any time without any prejudice.

The process to validate the accuracy of the collected data was adapted from Creswell and Creswell $(2018,193)$. Firstly, the researchers organised and prepared the data for 
analysis by collating the responses of the participants in line with the questions. Secondly, they read through all the data to provide a general sense of the data in accordance with the collated participants' responses and to reflect on the overall meaning. Thirdly, they started coding the data by supervisor, for example, Supervisor A, B, C, D and E. Fourthly, they represented the description and themes which appeared as major findings in qualitative studies. Lastly, they interpreted the meaning of the themes and descriptions by summarising the overall findings, comparing the findings with the literature, discussing personal views of the findings, and stating limitations and future research.

The two researchers are academics in an ODL institution in the CEDU at Unisa and have more than five years of experience in the same college. The researchers also have taught the undergraduate programmes to students who have enrolled for the BEd for more than five years. Furthermore, the researchers have conducted TP sessions with the undergraduate students for more than five years. Their background, knowledge, skills and interests qualify them to investigate the reflection on post-conference feedback as developmental teacher education strategy during TP sessions and to provide recommendations on the way in which the TP framework can be improved to further support pre-service teachers.

\section{Research Findings}

The findings of this study were generated from open-ended questionnaires which were administered to supervisors of pre-service teachers during TP. The findings delineate supervisors' views about TP and the benefits and pitfalls of post-conference feedback with pre-service teachers. Five supervisors returned the open-ended questionnaires and the researchers decided to report on these. The following themes were developed to analyse the data collected with the TP supervisors: supervisors' views about TP, benefits of post-conference feedback, and pitfalls of post-conference feedback.

\section{Supervisors' Views about Teaching Practice}

The supervisors viewed TP as a means of pre-service teachers' classroom teaching support, not as a policing initiative to expose their weaknesses. TP informs the supervisors about the main elements of relational practice which are representations, decompositions and approximation of practice according to Grossman et al. (2009). Abdulla and Mirza (2020) argue that this type of support enables pre-service teachers to become confident prospective teachers. For pre-service teachers to become confident teachers, they should fulfil the aforementioned three main elements of relational practice. Supervisor B stated:

I can say that teaching practice supervision is not some policing initiative to expose your inefficiency. Rather, a means to support you in the journey of becoming a confident teacher who can impart quality lessons that benefit all learners in the classroom. 
Supervisor B shows that this type of support empowers pre-service teachers to deliver lessons that can cater for all learners' needs during teaching and learning. For teachers to cater for all the learners' needs, they should know in which way to represent teaching professionally and they should know in which way to break down the components of TP, according to Grossman et al. (2009). Supervisor B also indicated that the support provided during TP sharpens pre-service teachers to become confident prospective teachers. This concurs with the approximation of practice in Grossman et al.'s (2009) study, which postulates that pre-service teachers are given an opportunity to perform teaching duties in preparation to become good professional teachers.

Furthermore, the findings show that TP enables supervisors to assess pre-service teachers if they can apply the knowledge and skills they have learned in their modules in practice. In other words, the assessment used by supervisors during TP is not summative but formative. This is AfL according to Broadfoot et al. (2002) which informs both the supervisor as teacher and learner as pre-service teacher about the evidence that can guide them about what learners know, where they need to go and how best to support them. The findings also indicate that this type of assessment can assist both supervisors and pre-service teachers to know the areas students mastered and areas of weaknesses so as to understand the type of support needed for improvement. Surucu, Unal and Yildirim (2017) concur that TP provides pre-service teachers with an opportunity to know their levels of skills, to correct specific mistakes, and to improve their weaknesses.

\section{Benefits of Post-Conference Feedback}

Post-conference feedback is a process of providing both the supervisors and pre-service teachers an opportunity for reflection on what had been achieved and what had not been achieved during classroom practice. In the reflection process, pre-service teachers may be able to reflect on the three aforementioned main elements of relational practice according to Grossman et al. (2009). Post-conference feedback can also be an assessment that helps supervisors and mentor teachers to develop pre-service teachers to become reflective and self-managing in the teaching and learning process (Broadfoot et al. 2002).

I take minutes with students after the lesson so that she or he can take a moment to reflect on his or her teaching. (Supervisor C)

The extract above supports the argument that post-conference feedback allows preservice teachers to reflect on what they have done during teaching and learning. Supervisor C used the phrase "after the lesson" to signify the time of the feedback with the pre-service teacher, which is after the lesson observations. Akcan and Tatar (2010) argue that post-conference feedback with the supervisor encourages reflections and helps pre-service teachers to critically evaluate their lessons during the feedback sessions. Feedback sessions can be an ongoing process of reflection and cooperation 
between the pre-service teachers, mentor teachers and university supervisors, as Kemmis et al. (2014) suggested.

Martinez-Agudo (2016) postulates that both mentor teachers and supervisors should provide pre-service teachers with feedback after the lessons. However, there are varied findings or even there is no consensus in previous studies or the findings had conflicting views as some supervisors worked jointly with mentor teachers and some did not in the post-conference process, which is important for both of them to develop the pre-service teachers. Supervisors A and C worked independently without mentor teachers unlike supervisors B, D and E. For example, the two supervisors A and C used the first person singular "I" and not the plural "we" to include the mentor teacher. This can create a gap in students' professional learning. In other words, some pre-service teachers had an opportunity to get feedback from both supervisors and mentor teachers while others did not, as expressed by Supervisor A:

I meet with the students in an office individually. The students explain to me how they feel about the lesson: I let the student rate themselves in terms of scores and tell me why what they are happy about and also indicate their area of improvement.

The foregoing excerpt shows that Supervisor A used the first person singular "I" referring to himself and used "students" three times in the extract referring to pre-service teachers during the post-conference feedback. But the mentor teachers are not mentioned in the feedback sessions, which shows that they were not involved. Unisa's manual (2012) advocates that mentor teachers are assigned to assist pre-service teachers with regular activities, practices, feedback and advice, yet it seems the pre-service teachers lack the support from mentor teachers during post-conference feedback to master the three components of relational practice that are necessary for the pre-service teachers to develop in professional learning (Grossman et al. 2009).

Copland, Ma and Mann (2009) postulate that during post-conference feedback, preservice teachers may be provided with both positive and negative evaluations of teaching and also give suggestions for improvement. The findings of this study show that post-conference feedback helps the pre-service teachers, mentor teachers and supervisors to identify the positive observations and gaps that need attention for improvement in professional learning. As mentioned earlier, post-conference feedback can be regarded as AfL as it is seen as recognising a range of achievements of students and enhancing effective planning of teaching and learning for pre-service teachers, as Broadfoot et al. (2002) advised. Furthermore, identifying achievements and areas of improvement may help pre-service teachers to know what they can deal with and the way in which they can improve their representation of practice, decomposition of practice and approximation of practice.

After that, I highlight the positives that I observed during the lesson, then I highlight the gaps and the student is offered a chance to suggest points of improvement if it is necessary. (Supervisor C) 
The foregoing extract shows that post-conference feedback presents supervisors and mentor teachers with an opportunity to understand the good practice of the pre-service teachers. The supervisors and mentor teachers may also be able to gauge what preservice teachers know, what they need to know and how best to know the practices that would meet the learners' needs during teaching and learning, as Grossman et al. (2009) suggested. In fact, Calleja et al. (2016) argue that feedback sessions can promote preservice teachers' teaching skills and can consolidate their pedagogical skills.

The findings revealed that post-conference feedback encourages learning that motivates pre-service teachers about their progress and achievements during TP. The supervisors who returned the questionnaires stressed that post-conference feedback as the session which provide pre-service teachers with constructive feedback, appeared to have motivated them to go back to class and apply their knowledge and skills gained during the sessions. Broadfoot et al. (2002) suggest that motivation of students can be enhanced through assessment that can protect students' autonomy, give constructive feedback and also create an opportunity for self-direction. Through motivation, relational practices such as representation of practice, approximation of practice and decomposition of practice can be improved during feedback sessions for the pre-service teachers to become good professional teachers (Grossman et al. 2009). Supervisor B stated:

\begin{abstract}
Yes, it does. Our UNISA students do not usually have the luxury of face to face intervention with lecturers. Showing them how they need to teach gives them clarity on how to apply the theory that is in their study material into practice. Students appreciate the support very much. They end up inviting you for a second visit whereby they want you as the supervisor to go and observe them as they put what you have taught them into practice.
\end{abstract}

As the pre-service teachers are ODL students, they do not have the opportunity to meet with their lecturers; this platform allows them to engage with their supervisors to understand the way in which they should apply theories learned in their study materials to practice. According to Surucu, Unal and Yildirim (2017), theoretical knowledge is essential only when pre-service teachers possess the knowledge, skills, attitude and behaviors they need in classroom practice. The extract shows that students have a chance to get clarity on what they have learned in their modules and that they must apply them through TP sessions. According to the extract, the pre-service teachers appeared to be motivated by the post-conference feedback conducted after their lesson presentations. This is informed by the supervisor who stated that "they end up inviting you for a second visit" to demonstrate skills and knowledge gained during feedback sessions.

\title{
Pitfalls of Post-Conference Feedback
}

The findings also highlighted some pitfalls that impede the progress of post-conference feedback during TP sessions. The time factor was found to be one of the challenges that affect the interaction between the supervisor and pre-service teachers during post- 
conference feedback. This is affected by the time allocated to supervisors to observe each student once, meaning classroom observations are once-off during TP sessions. The supervisors and pre-services appear not to have enough time to reflect on the way in which teaching is represented professionally and the way in which the decomposition of practice is carried out during TP sessions (Grossman et al. 2009). AfL may also be affected as the supervisors may not know how best they can provide further remedial support to pre-service teachers.

I mostly observe a student once and this does not assist students that much. (Supervisor A)

I have observed my student once, therefore, it is almost once off observation and the lesson will take about 30 or 40 minutes. Thereafter, it is over with the student. (Supervisor E)

The foregoing extracts show that the time allocated for supervision of pre-service teachers is not enough to support and provide feedback to the students. Supervision is seen as a once-off incident and that cannot guarantee the effectiveness of postconference feedback to pre-service teachers. Supervisors are unable to measure the improvement of the pre-service teachers within the mentioned time constraints.

The supervisor-pre-service-teacher ratio is $1: 10$ per week, which may not be feasible owing to the distance to be travelled by supervisors between schools. The development of pre-service teachers in professional learning appears to be suffering as supervisors would be keen to cover the scope of work and assess all pre-service teachers allocated to them for a week.

Given the number of days (5 days) and the number of students I am expected to support (10 students a week and should at least supervise a minimum of two students a day, which in some cases is not possible given the distance I drive) I mostly observe a student once and this does not assist students that much. More time should be allocated to supervisors to make follow up to the lesson. (Supervisor A)

The foregoing extract delineates the number of days given to the supervisors to supervise pre-service teachers as being insufficient for interaction with the students. Supervisor A explains that the distance they travel between schools affects the quality of feedback as time becomes limited for the supervisors and pre-service teachers to interact during TP. Supervisor A indicates that they cannot follow up on the progress and achievement for the pre-service teacher owing to the pressure they are under during TP sessions.

The commitment of some mentor teachers during post-conference feedback was mentioned by the supervisors. The Unisa (2012) manual specifies that supervisors and mentor teachers are assigned to assist pre-service teachers with activities, practices, feedback and advise on a regular basis. According to this manual, supervisors and 
mentor teachers are assigned to work together to support pre-service teachers in the professional teaching to avoid conflicting ideas towards their inputs and comments during feedback sessions. The findings showed that some mentor teachers are not committed to pre-service teachers during TP sessions, which can have a negative effect on the progress of pre-service teachers. This cannot be assessment that can encourage learning in which students can be motivated by their supervisors by emphasising progress and achievement rather than a pass or failure.

\section{Discussion}

Although this research focused on post-conference feedback as a developmental strategy to support pre-service teachers, the researchers needed to first understand how TP supervisors view TP. This section discusses the findings of this study which focused on the views of supervisors of TP as a point of departure to understand their background about TP and then the post-conference feedback during TP sessions. The findings of this study revealed the way in which TP supervisors viewed TP in schools and the way in which post-conference feedback plays a role to pre-service teachers during TP.

The findings of this study revealed that TP was not meant to be a policing mechanism, but to support students in improving their pedagogical skills and knowledge, as Copland (2010) advised. In other words, TP was not implemented to criticise pre-service teachers, instead it is implemented to develop them to become good prospective teachers (Abdulla and Mirza 2020) through oral and written interaction (Ali and Al-Adawi 2013). Moreover, TP supervisors can assess pre-service teachers' skills and knowledge during TP. This showed that TP supervisors were able to understand the way in which pre-service teachers' teaching was represented professionally, the way in which the breaking down of the components of TP was done, and the way in which they performed their duties to become good professional teachers.

Calleja et al. (2016) found that post-conference feedback promotes pre-service teachers' thinking and consolidates their pedagogical skills. The findings of this study show that post-conference feedback enables the pre-service teachers to reflect on their classroom TPs. During reflection, the pre-service teachers had an opportunity to identify the strengths and weakness during TP. This can support Akcan and Tatar's (2010) findings that reflections during post-conference help pre-service teachers to critically evaluate their lessons. Reflections during post-conference feedback can, therefore, enable preservice teachers to know the areas that need improvement during TP. The reflections also helped supervisors to identify the areas of weaknesses that inform them of the way in which to improve their TP framework. This appears to motivate pre-service teachers in their progress and achievement during TP.

Martinez-Agudo (2016) argues that the post-conference feedback should be effective to satisfy pre-service teachers during TP. The satisfaction of pre-service teachers during post-conference may help them to set goals for their improvement. The supervisors 
revealed that pre-service teachers showed satisfaction with the post-conference feedback as they requested them to come back to observe if they applied what they had learned during the sessions. Furthermore, pre-service teachers requested supervisors to visit them again to monitor their progress and achievement during TP sessions.

However, the findings identified some pitfalls that affected the progress of postconference feedback during TP. Firstly, the findings revealed that time was a challenge for both the pre-service teachers and supervisors for the feedback owing to schools that are situated far apart. According to Gürsoy (2013), the limited time allocated for the pre-service teachers and supervise for TP can cause inconsistencies in the teacher education, which may hinder them from becoming good prospective teachers. Furthermore, the lack of time for post-conference feedback may contribute towards bridging theory and practice during TP.

In addition, the supervisor-pre-service-teachers' ratio of 1:10 proved to be another pitfall that impeded the post-conference feedback. The findings revealed that each supervisor was expected to supervise 10 pre-service teachers in five days which was practically impossible as mentioned. Furthermore, the supervisors may not provide constructive feedback as they would be expected to cover the scope of the work for that week. Copland (2010) investigated tension in the post-conference feedback that limits pre-service teachers from understanding the rules to follow during TP and this may result in the pre-service teachers not following the rules of TP.

Lastly, the findings showed that some mentor teachers were not actively involved during TP as some of the supervisors did not mention their participation in their responses on the post-conference feedback. This is contrary to Unisa's (2012) requirement which states that both supervisors and mentor teachers should be present when observing and assessing pre-service teachers during TP. The participation of mentor teachers, or the lack thereof, may cause tension as quantity and quality of feedback provided by supervisors and mentor teachers in different times may differ (Gürsoy 2013). Hollard (2005) concurs that assessment and supervision may cause tension if conducted at different times by supervisors and mentor teachers owing to the feedback that may confuse pre-service teachers during TP. Therefore, an aligned commitment by supervisors and mentor teachers may alleviate the conflicting ideas that they may possess for pre-service teachers during the post-conference feedback.

\section{Implications for Practice}

- There is a need for clear and specific outcomes for the assessment of TP.

- A self-assessment rubric is needed for pre-service teachers to avoid conflict during post-conference scoring.

- More strategic professional development workshops on post-conference feedback are needed. 


\section{Conclusion}

This study investigated the experiences of supervisors regarding post-conference feedback with pre-service teachers during TP. The findings of this study showed that post-conference feedback has pockets of benefits for both pre-service teachers and supervisors. For pre-service teachers, post-conference feedback has been used to improve their pedagogical practices through reflection on lessons and discussions with their supervisors. Supervisors, on the other hand, had an opportunity to assess preservice teachers when teaching learners during TP. Time, supervisor-pre-serviceteacher ratio, and commitment of some mentor teachers were found to be some challenges related to post-conference feedback which can hinder the progress of preservice teachers during TP. The study suggests that the TP framework be revised to improve the practices of ODL pre-service teachers towards alleviating the pitfalls that were highlighted.

\section{References}

Abdullah, N. A., and M. S. Mirza. 2020. "Evaluating Pre-Service Teaching Practice for Online and Distance Education Students in Pakistan: Evaluation of Teaching Practice."

International Review of Research in Open and Distributed Learning 21 (2): 81-97. https://doi.org/10.19173/irrodl.v21i2.4606.

Ali, H. I. H., and H.A. Al-Adawi. 2013. "Providing Effective Feedback to EFL Student Teachers." Higher Education Studies 3 (3): 21-35. https://doi.org/10.5539/hes.v3n3p21.

Akcan, S., and S. Tatar. 2010. "An Investigation of the Nature of Feedback Given to PreService English Teachers during their Practice Teaching Experience." Teacher Development 14 (2): 153-72. https://doi.org/10.1080/13664530.2010.494495.

Brandt, C. 2008. "Integrating Feedback and Reflection in the Teacher Preparation." ELT Journal 62 (1): 37-46. https://doi.org/10.1093/elt/ccm076.

Broadfoot, P. M., R. Daugherty, J. Gardner, W. Harlen, M. James, and G. Stobart. 2002. Assessment for Learning: 10 Principles. Cambridge: University of Cambridge School of Education.

Calleja, P., T. Harvey, A. Fox, and M. Carmichael. 2016. "Feedback and Clinical Practice Improvement: A Tool to Assist Workplace Supervisors and Students." Nurse Education in Practice 17: 167-73. https://doi.org/10.1016/j.nepr.2015.11.009.

Copland, F. 2008. "Deconstructing the Discourse: Understanding the Feedback Event. In Professional Encounters in TESOL, 5-23. London: Palgrave Macmillan.

Copland, F. 2010. "Causes of Tension in Post-Observation Feedback in Pre-Service Teacher Training: An Alternative View." Teaching and Teacher Education 26: 466-72. https://doi.org/10.1016/j.tate.2009.06.001. 
Copland, F. 2011. "Negotiating Face in Feedback Conference: A Linguistic Ethnographic Analysis." Journal of Pragmatics 43: 3832-43.

https://doi.org/10.1016/j.pragma.2011.09.014.

Copland, F., G. Ma, and S. Mann. 2009. "Reflecting in and on Post-Observation Feedback in Initial Teacher Training on Certificate Courses.” ELTED 12: 14-22.

Creswell, J. W., and J. D. Creswell. 2018. Research Design: Qualitative, Quantitative, and Mixed Methods Approaches. 5th ed. Thousand Oaks: Sage.

Grossman, P., C. Compton, D. Igra, M. Ronfeldt, E. Shahan, and P. Williamson. 2009. "Teaching Practice: A Cross-Professional Perspective." Teachers College Record 111 (9): 2055-100.

Gürsoy, E. 2013. "Improving Practicum for a Better Teacher Training." Procedia - Social and Behavioral Sciences 93: 420-25. https://doi.org/10.1016/j.sbspro.2013.09.214.

Holland, P. 2005. "The Case of Expanding Standards for Teacher Evaluation to Include an Instructional Supervision Perspective." Journal of Personnel in Education 18 (1): 67-77. https://doi.org/10.1007/s11092-006-9009-0.

Kale, M. 2011. "Problems Encountered in Teaching Practice of Teachers' Course." Turkish Journal of Educational Sciences 9 (2): 255-80. https://dergipark.org.tr/en/download/article-file/256212.

Kemmis, S., H.L. T. Heikkinen, G. Fransson, J. Aspfors, and C. Edward-Groves. 2014. "Mentoring a New Teacher as a Contested Practice: Supervision, Support and Collaborative Self-Development." Teacher and Teacher Education 43: 154-64. https://doi.org/10.1016/j.tate.2014.07.001.

Martinez Agudo, J. 2016. "What Type of Feedback do Student Teachers Expect from their School Mentors during Practicum Experience? The Case of Spanish EFL Student Teachers." Australian Journal of Teacher Education 41 (5): 35-51. https://doi.org/10.14221/ajte.2016v41n5.3.

Surucu, A., A. Unal, and A. Yildirim. 2017. "Evaluation of Teaching Practice Course Teachers according to Opinions of Math Teacher Candidates." International Journal of Research in Education and Science 3 (1): 107-13.

Sutton, R. 1995. Assessment for Learning. Salford: RS Publications.

Tang, S. Y. F., and A. W. K. Chow. 2007. "Communicating Feedback in Teaching Practice Supervision in a Learning-Oriented Field Experience Assessment Framework." Teaching and Teacher Education 23: 1066-85. https://doi.org/10.1016/j.tate.2006.07.013.

Unisa. 2012. Supporting Teaching Practice: A Manual for Supervisors and Mentors. Pretoria: Unisa.

Wells, L., and M. McLoughlin. 2014. "Fitness to Practice and Feedback to Students: A Literature Review." Nurse Education Practice 14: 137-41. https://doi.org/10.1016/j.nepr.2013.08.006. 


\section{Appendix}

Dear Participant

We, Dr Tšhegofatšo Makgakga and Prof. Sindile Ngubane, are conducting a study "Reflection on post-conference feedback as a developmental teacher training strategy: Teaching practice supervisors' experiences in an ODL institution" and we request your participation in this study by filling out this questionnaire that will take you approximately 20 to 25 minutes. This study intends to share the ODL supervisors' reflections on post-conference feedback as a pre-service teachers support strategy during teaching practice supervision. Your name will not be disclosed as pseudonyms will be used for all the participants and the information you give us will be treated with confidentiality.

Your participation in this study will be highly appreciated.

Questionnaire

1. What are your views about TP supervision for pre-service teachers?

2. What is the purpose of conducting post-conference feedback?

3. How do you conduct post-conference feedback for pre-service teachers to reflect on their lessons?

4. What challenges (if any) do you face as supervisors during post-conference sessions?

5. What are students' challenges during post-conference sessions?

6. Does post-conference feedback provide students with an opportunity to reflect on their own lessons? If yes/no, why?

7. Does the feedback help to develop students' professional learning and improve TP skills? If yes/no, why?

8. What are your general comments and reflections on post-conference feedback during TP?

9. How many times and how long do you observe each student during TP supervision?

10. Is the time allocated for the TP supervision enough to support students? If yes/no, why?

11. What can be done to improve the ODL TP framework? 